\title{
O MÉTODO APAC COMO MODELO DE HUMANIZAÇÁO DO PROCESSO IDENTITÁRIO DO ENCARCERADO
}

\author{
THE APAC METHOD HOW A MODEL OF HUMANIZING THE IDENTITY \\ PROCESS OF THE PRISIONER
}

\author{
Roberto Carvalho Veloso ${ }^{\mathrm{I}}$ \\ Cristian de Oliveira Gamba ${ }^{\mathrm{II}}$
}

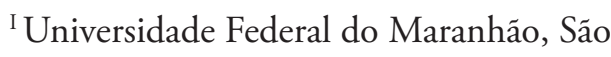
Luís, MA, Brasil. Doutor em Direito.

E-mail: velosorc@uol.com.br

II Universidade Federal do Maranhão, São Luís, MA, Brasil. Mestrando em Direito.

E-mail: cristianjr34@hotmail.com

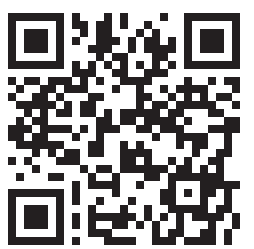

DOI: http://dx.doi.org/10.31512/rdj.v21i40.407

Recebido em: 01.11.2019

Aceito em: 29.02.2020
Resumo: A (in)eficiência do atual modelo de gestão carcerária apresenta-se como questão cada vez mais recorrente. Em que pese a existência de um cenário onde os índices de encarceramento encontram-se elevados, o que se verifica, na prática, é uma manutenção do estado de intranquilidade social. Sendo assim, surge a necessidade de se repensar o atual modelo prisional brasileiro e apontar alternativas viáveis que possam contribuir para melhoria deste quadro. É justamente neste contexto que o presente trabalho pretende analisar, debater e examinar o método proposto pela Associação de Assistência e Proteção aos Condenados (APAC), com enfoque no processo identitário do encarcerado, procurando compatibilizá-lo com o postulado constitucional da dignidade da pessoa humana. Para o cumprimento desta diretiva será realizada uma análise comparativa com o modelo tradicional de gestão penitenciária. Empregouse a vertente metodológica histórico-social como modo de realização do presente estudo. Ao final, defende-se que a APAC, apesar de possuir imperfeiçóes e, em alguns pontos, reproduzir o modelo tradicional, apresenta-se como uma alternativa de execução penal mais humanizada, que trabalha o processo identitário do encarcerado através do paradigma da autonomia e em conjunto com a comunidade junto a qual o indivíduo será reinserido após o cumprimento da pena.

Palavras-chave: Execução Penal. Dignidade da pessoa humana. Identidade. APAC.

\footnotetext{
Abstract: The (in)efficiency of the current prison management model presents itself as an increasingly recurring issue. In spite of the existence of a scenario where the incarceration rates are high, what is verified, in practice, is a maintenance of the state of social unrest. Thus, there is a need to rethink the current Brazilian prison model and point out viable alternatives that can contribute to improving this situation. It is precisely in this context that the present work intends to analyze, debate and examine the method proposed by
} 
the Association of Assistance and Protection to Convicts (APAC), focusing on the prisoner's identity process, seeking to make it compatible with the constitutional postulate of the dignity of the human person. In order to comply with this directive, a comparative analysis will be carried out with the traditional model of prison management. The historicalsocial methodological aspect was used as a way of carrying out the present study. In the end, it is argued that APAC, despite having imperfections and, in some points, reproducing the traditional model, presents itself as an alternative of more humanized criminal execution, which works the identity process of the prisoner through the paradigm of autonomy and together with the community to which the individual will be reinserted after serving the sentence.

Keywords: Criminal Execution. Dignity of human person. Identity. APAC.

\section{Consideraçóes iniciais}

A problemática atinente à eficiência do atual modelo de execução penal se apresenta como uma questão cada vez mais desafiadora, principalmente quando se trata do modo de cumprimento das penas privativas de liberdade. Ao mesmo tempo em que se reconhece a dificuldade do atual modelo carcerário em cumprir a função ressocializadora da pena, principalmente em virtude de óbices estruturais e conceituais, visualiza-se a existência de um árduo trabalho na busca por alternativas viáveis, cujo dispêndio encontra óbice na multidimensionalidade do objeto enfrentado, uma vez que as temáticas pertinentes à criminalidade envolvem fatores históricos, culturais, sociais e econômicos que possuem raízes bastante profundas.

Em que pesem as alterações na legislação alusiva à execução penal, sobretudo após o advento da Constituição Federal de 1988, além da ratificação de tratados internacionais de Direitos Humanos e da edição da Lei de Execuções Penais (Lei 7.210 de 1984), que possuem como objetivo comum à humanização das penas, o que se percebe na prática é a existência de um sistema carcerário marcado pelo desrespeito aos direitos fundamentais da pessoa humana e um verdadeiro abandono da função ressocializadora da pena.

Este abandono tem sido fomentado por um movimento crescente de invisibilidade das problemáticas atinentes ao encarcerado. Neste viés o preso passa a ser alguém sem face, identidade e projetos, sendo concebido como um sujeito a ser controlado e submetido a uma ordem estabelecida.

Outro fator que contribui para o esquecimento do apenado consiste no crescimento de movimentos sociais que pleiteiam o recrudescimento das penas e da execução penal, partindo do pressuposto que a aplicação mais rigorosa do direito penal será capaz de propiciar uma reduçáo da criminalidade. Neste cenário, o preso passa a ser visto como um inimigo da sociedade e a 
prisão passa a ser considerada unicamente como um espaço de segregação social, destinada a acolher os indivíduos perigosos ${ }^{1}$.

Deste modo, o presente trabalho almeja se debruçar sobre a figura do encarcerado, mais especificamente sobre os impactos que o período de segregação social geram em seu processo de construção identitária. Para isto, utilizou-se, através da vertente metodológica histórico-social, a pesquisa documental e bibliográfica, sendo que a interpretação das informaçóes obtidas foi realizada com o auxílio das teorias acerca da criminologia crítica e dos direitos humanos.

Dentro desta perspectiva buscar-se-á, inicialmente, delinear o conceito de identidade a ser adotado neste trabalho, partindo-se da noção de que se trata, essencialmente, de uma construção social marcada pelo paradigma da transitoriedade e da incompletude (CIAMPA, 1984). Ainda neste tópico serão traçadas as principais diretrizes do processo de construção da identidade em um mundo capitalista e globalizado, principalmente de acordo com os ensinamentos propostos por Bauman (1998). Ressalte-se ainda que toda leitura deste conceito será realizada a partir de um diálogo constante com o princípio da dignidade da pessoa humana, elencado como um dos fundamentos do Estado Democrático de Direito pela Constituição Federal de 1988.

Posteriormente será realizada uma incursão sobre as características do modelo tradicional de gestão carcerária - atualmente implantado na maioria dos presídios nacionais - realçando seus impactos no processo de construção da identidade dos apenados.

Por fim, será analisado o modelo de execução penal desenvolvido pela Associação de Assistência e Proteção aos Condenados (APAC), que possui como princípios basilares a valorização humana e o respeito a individualidade do encarcerado (OTTOBONI, 2001). Neste ponto, serão analisadas, debatidas e examinadas as principais vantagens e desvantagens deste modelo para que, ao final, seja defendida sua viabilidade como alternativa efetiva ao atual paradigma predominante de execução penal.

\section{$2 \mathrm{O}$ conceito de identidade à luz do princípio da dignidade da pessoa humana}

O primeiro objetivo deste labor é definir o conceito de identidade que guiará esta abordagem. Tendo em vista a centralidade da Constituição Federal no ordenamento jurídico nacional, bem como a necessidade de que todos os ramos do direito sejam interpretados a partir de seu filtro axiológico, faz-se necessário que tal conceito seja analisado a partir de uma estreita correlação com os postulados constitucionais, em especial no que diz respeito ao princípio da dignidade da pessoa humana.

Antes disto, contudo, se faz necessário definir as matizes sociológicas do conceito de identidade. Para isto, parte-se da ideia de que se trata de um fenômeno social, que se constrói e se transforma de acordo com as vivências do sujeito diante de seu meio. Camargo e Ferreira

1 Dentro deste contexto surgem doutrinas do direito penal que defendem uma crescente intensificação do aparato repressivo no trato com a criminalidade. Neste sentido, consultar a doutrina do direito penal do inimigo, conforme proposta por Jakobs e Meliá (2018). 
(2013, p. 186) aduzem que "as concepçóes de realidade, constituintes do mundo simbólico da pessoa, são desenvolvidas socialmente, através de um processo dialético em que o indivíduo é coprodutor tanto da sociedade como de si próprio".

Justamente por ser um fenômeno social o processo de construção da identidade assumiu diversas características a depender do momento histórico em que se situa a análise. Bauman (1998) aponta que o surgimento da modernidade, acompanhada das diversas mudanças na organização econômica e social, trouxe alteraçôes significativas ao entendimento da identidade.

Segundo o autor, em momentos passados, a identidade era algo grupal, imposto pela coletividade. Isto ocorria principalmente em virtude da existência de pequenos grupos sociais, marcados pela vigilância constante dos membros, fato este que constituía um empecilho para o desenvolvimento da autonomia. Neste contexto, a identidade era, primordialmente, uma atribuição e não uma construção do sujeito em sociedade (BAUMAN, 1998).

Contudo, o surgimento da modernidade, marcada pela globalização, movimento caracterizado pelo intercâmbio constante de ideias, informaçóes e produtos entre diferentes povos e culturas, dificultou a existência de grupos sociais fechados e isolados. Além disto, a modernidade trouxe como atributo marcante a transitoriedade das relaçóes, sendo que a durabilidade não é mais tão relevante quanto no passado, pois habita-se um mundo pautado pela lógica do consumo. Neste cenário a própria identidade se torna algo consumível e, por isso, eminentemente transitória.

O mundo construído de objetos duráveis foi substituído pelo de produtos disponíveis projetados para imediata obsolescência. Num mundo como esse, as identidades podem ser adotadas e descartadas como uma troca de roupa. O horror da nova situação é que todo diligente trabalho de construção pode mostrar-se inútil; o fascínio da nova situação, por outro lado, se acha no fato de não estar comprometida por experiências passadas, de nunca ser irrevogavelmente anulada, sempre mantendo opçóes abertas (BAUMAN, 1998, p. 112-113).

Dentro desta perspectiva pode-se concluir que a construção da identidade não pode ser mais considerada uma mera atribuição do grupo social, sendo inviável a exclusão da dimensão individual neste processo. Sendo assim, alterna-se para um paradigma em que a identidade se apresenta como um construção dialética entre as esferas individual e social, elaborada através da apropriação autônoma das experiências e valores sociais, ou seja, qualquer projeto de reconstrução da identidade dos indivíduos deve pautar-se no desenvolvimento da assunção autônoma de novos estilos de vida.

Também é possível destacar que a identidade, dentro do contexto da pós-modernidade, se apresenta sempre como algo inacabado e incompleto, ou seja, está em permanente processo de construção. Ciampa (1984) destaca que esta construção se baseia numa constante metamorfose, em que o indivíduo se apresenta como alguém que nega constantemente a si mesmo e náo se deixa cristalizar dentro de uma identidade pressuposta e anteriormente dada. 
Neste aspecto, rejeita-se qualquer explicação metafísica da identidade que venha a considerá-la como algo estático, atemporal e desvinculado de uma realidade social subjacente. Em contraponto, é concebida como um fenômeno em constante movimento, desenvolvido dentro de um contexto histórico específico. Ciampa destaca que o grande perigo para a identidade na modernidade é a sua cristalização, ou seja, a perda desse movimento inerente:

Só posso comparecer no mundo frente a outrem efetivamente como representante de meu ser real quando ocorrer à negação da negação, entendida como deixar de presentificar uma apresentaçấo de mim que foi cristalizada em momentos anteriores - deixar de repor uma identidade pressuposta - ser movimento, ser processo, ou, para utilizar uma palavra mais sugestiva se bem polêmica, ser metamorfose (1984, p. 70).

Bauman trabalha a mesma perspectiva dispondo que o "eixo de estratégia da vida pósmoderna não é fazer a identidade deter-se, mas evitar que se fixe” (1998, p. 114), sendo que qualquer medida que visa a reinserção do indivíduo ao corpo social deve estimular um processo de construção da identidade pautada na autonomia e em sua constante metamorfose.

Este entendimento acerca do conceito de identidade também encontra guarida no ordenamento jurídico nacional, principalmente no que tange aos seus postulados basilares, em especial o princípio da dignidade da pessoa humana, destacado como um dos fundamentos do Estado Democrático de Direito.

A amplitude de tal princípio acaba por impedir a existência de conceitos unívocos ou unidimensionais, todavia a maioria das definiçóes parece coincidir naquilo que seja seu núcleo essencial, que consiste na possibilidade de autodeterminação humana, promovendo sua participação ativa nos desígnios sociais. Neste sentido a definição de Sarlet:

Assim sendo, temos por dignidade da pessoa a qualidade intrínseca e distintiva reconhecida em cada ser humano que o faz merecedor do mesmo respeito e consideração por parte do Estado e da comunidade, implicando, neste sentido, um complexo de direitos e deveres fundamentais que assegurem a pessoa tanto contra todo e qualquer ato de cunho degradante e desumano, como venham a lhe garantir as condiçóes existenciais mínimas para uma vida saudável, além de propiciar e promover sua participação ativa e corresponsável nos destinos da própria existência e da vida em comunhão com os demais seres humanos, mediante o devido respeito aos demais seres que integram a rede da vida (2011. p. 113).

Busca-se evitar, através deste princípio, a submissão humana a qualquer tipo de interesse "tratando cada pessoa como fim em si mesma, nunca meio (coisas) para satisfaçáo de outros interesses ou interesses de terceiros" (FERNANDES, 2013. p. 300). Segundo Guerra, sua constitucionalização vem acompanhada de uma série de diretrizes que nortearão a própria atuação estatal, sendo estas:

a) reconhecer a pessoa como fundamento e fim do Estado; b) contribuir para a garantia da unidade da Constituição; c) impor limites à atuação do poder público e à atuação dos cidadãos; d) promover os direitos fundamentais; e) condicionar a atividade do intérprete; f) contribuir para a caracterização do mínimo existencial (2003, p. 182). 
Pode-se dizer que, no contexto de um Estado Democrático de Direito, o respeito ao princípio da dignidade da pessoa humana traz ao ente estatal a obrigação de fornecer aos cidadáos o substrato básico de direitos, que devem ser universalmente garantidos, para que o ser humano tenha a possibilidade de exercer, amplamente, suas possibilidades existenciais, ou seja, para que possa construir sua identidade através do paradigma da autonomia.

Destaca-se que o respeito a tal princípio deve ser garantido a todos de forma indiscriminada, não se destinando apenas aqueles considerados dignos dentro de um grupo social específico. Neste caso, os direitos fundamentais não se tratam de algo a ser conquistado, mas sim de algo já possuído, do qual o indivíduo já é titular simplesmente por ostentar a condição de ser humano.

Ao situar tal raciocínio na seara da execução penal percebe-se que o respeito a tal princípio apresenta-se como baliza fundamental de um sistema penal que busca propiciar a reinserção social do condenado. $\mathrm{O}$ artigo inaugural da Lei de Execuçóes Penais denota justamente esta preocupação dispondo que "a execução penal tem por objetivo efetivar as disposiçóes de sentença ou decisão criminal e proporcionar condiçôes para a harmônica integração social do condenado e do internado" (BRASIL, 1984).

Desta forma, qualquer modelo de execução penal comprometido com a reinserção social deve primar por um processo de resgate da autonomia do apenado, apresentando possibilidades para que desenvolva sua vida pós-cárcere através da assunção de novos papéis sociais, evitando a fixação de sua identidade.

Todavia, o que se verá a seguir, através da análise do atual modelo de execução penal, é que tais diretrizes não encontram respaldo na realidade, seja pelas dificuldades estruturais do ambiente carcerário, seja pelos aspectos conceituais que fundamentam o atual modo de organização do sistema prisional.

\section{0 processo de construçáo da identidade do encarcerado no modelo tradicional de gestáo carcerária}

Entende-se por modelo tradicional de gestão carcerária aquele majoritariamente aplicado no país em sede de execução penal. Este paradigma se pauta, essencialmente, na concepçáo da prisão como uma instituiçáo total, conforme o conceito cunhado por Erving Goffman.

Segundo as construçóes teóricas do mencionado autor, a instituição total seria, primordialmente, "um local de residência e de trabalho onde um grande número de indivíduos com situação semelhante, separados da sociedade mais ampla por um período considerável de tempo, levam uma vida fechada e formalmente administrada" (GOFFMAN, 1987, p. 11). Os presídios seriam apenas uma das espécies de instituição total "criadas para proteger a comunidade contra ameaças e perigos intencionais, sem se importar muito com o bem-estar das pessoas segregadas" (BENELLI, 2014, p. 24). 
Estas instituições possuem algumas características marcantes, sendo elas: a submissão de seus integrantes a um rígido controle e disciplina, a sua segregação social e a limitação na representação de papéis sociais (GOFFMAN, 1987). Todos estes aspectos encontram-se presentes no atual modelo de gestão carcerária predominante no Estado brasileiro e possuem implicaçóes relevantes no processo de reconstrução da identidade do encarcerado.

A segregação social é consequência direta da aplicação da pena privativa de liberdade, sendo a principal manifestação de sua função retributiva. Os presídios são espaços destinados a receber os indivíduos que violaram normas consideradas essenciais pelo corpo social e, com isso, buscam garantir uma desejável pacificação social através da retirada deste grupo do convívio coletivo.

Já quando se trata da limitação na representação de papéis sociais busca-se destacar que, no momento da entrada no cárcere, o indivíduo se separa de todos os seus vínculos anteriores (comunidade, família, etc.) - ou então os mantém apenas esporadicamente - em prol da inserção em um novo sistema, pautado por vínculos e valores essencialmente distintos daqueles presentes no seio social.

Barreto (2006) denomina este movimento como "prisionalização" ou "institucionalização", caracterizando-o pela internalização de uma série de regras e códigos de conduta que apenas tem valia no ambiente institucional. Enquanto na vida liberta o sujeito representa uma multiplicidade de papéis sociais, nas instituiçóes totais passa a exercer, integralmente, um papel singular, o de encarcerado.

A vivência deste movimento gera consequências adversas ao futuro processo de reinserção social do apenado, uma vez que trabalha-se a sua identidade sem considerar a devida aproximaçáo com a multiplicidade de papéis a serem exercidos no ambiente social. Sintoma deste processo é a ausência de qualquer participação da comunidade no processo de execução penal, em que pese a presença de tal diretiva na Lei de Execuçôes Penais.

Após serem libertos, os ex-presidiários sentem dificuldade em estabelecer relaçóes interpessoais como consequência das experiências carcerárias. $\mathrm{O}$ retorno ao mundo liberto é um período de transição que causa sofrimento ao indivíduo. A adaptação ao mundo livre exige uma ressignificaçáo de crenças e valores na maioria das vezes antagônicos aos assimilados durante o período de aprisionamento (BARRETO, 2006, p. 597).

Dito isto, se aprofundará, nos tópicos seguintes, outros óbices referentes a implementação de um processo de reconstrução da identidade do encarcerado que paute-se no paradigma da autonomia, condizente com o princípio da dignidade da pessoa humana. Primeiramente, serão destacadas as dificuldades de cunho estrutural, relacionadas as insuficiências quantitativas do atual sistema carcerário, e, posteriormente, as dificuldades conceituais, em especial o abandono histórico do processo de humanização das penas. 


\subsection{Breve panorama sobre o modelo tradicional de gestáo carcerária}

Neste momento o objetivo será de apresentar a realidade carcerária vivenciada nos estabelecimentos prisionais brasileiros, primando por demonstrar as dificuldades estruturais existentes no atual modelo de execução penal. Para isto, serão utilizados os dados quantitativos trazidos pelo Levantamento Nacional de Informações Penitenciárias, produzido no ano de 2019.

Segundo este levantamento o Brasil possuía, até dezembro de 2019, uma população prisional de 748.009 pessoas. Entre os anos de 1990 e 2016 o contingente prisional brasileiro se expandiu em 707\%, tendo havido crescimento da população carcerária em todos os anos durante este interregno temporal. Este movimento vem acompanhado de um aumento no déficit de vagas existentes no sistema carcerário, sendo que até a publicação deste estudo o sistema carcerário brasileiro possuía 442.349 vagas disponíveis, resultando numa taxa de ocupação prisional de 169\% (BRASIL, 2019).

Estes números refletem a superlotação dos estabelecimentos prisionais nacionais, fator este que, somado às péssimas condiçóes estruturais e de higiene dos presídios, acaba por criar um cenário aversivo para a realização de qualquer tipo de trabalho que vise à reinserção social dos apenados em condiçóes dignas.

Sintoma deste quadro é o baixo oferecimento de atividades que auxiliem o preso na criação de perspectivas de vida pós-cárcere. Na realidade penitenciária nacional apenas 16,53\% dos apenados estão envolvidos com alguma atividade educativa, seja o ensino escolar (alfabetização, formação em ensino fundamental, ensino superior, cursos de formação inicial e continuada) ou atividades complementares, enquanto apenas $19,28 \%$ da população prisional realiza algum tipo de trabalho, sejam atividades internas ou externas (BRASIL, 2019).

Os dados estatísticos também possibilitam a confecção do perfil do encarcerado brasileiro. Em geral, possuem entre 18 e 34 anos (74\%), são negros (64\%), com baixo grau de escolaridade (61\% não possuem ensino fundamental completo ou são analfabetos), sendo que aproximadamente $65 \%$ chegam ao cárcere em virtude do cometimento de crimes patrimoniais (roubo, furto e receptação) ou tráfico de drogas (BRASIL, 2016). A existência deste perfil não decorre da existência de uma maior propensão destes sujeitos à prática delitiva, mas são perpassadas por uma série de fenômenos sociais, culturais e econômicos de grande complexidade².

Silva, Mattos e Chaves (2018) dispóem que a criminalidade não está relacionada a uma qualidade intrínseca do sujeito, mas trata-se de uma etiqueta imposta a determinados indivíduos. Prosseguem dispondo que "existe uma imensa amálgama de pessoas que cometem determinado delito, porém apenas uma parcela desses indivíduos são investigados, processados, julgados e condenados" (2018, p. 207). Desta forma, a existência de um perfil predominante de encarcerado

2 Wacquant (2003) propóe que a nova gestão do sistema penal, desenvolvida em meados do século passado nos Estados Unidos, contribuiu significativamente para a criminalização de determinados grupos sociais, principalmente as parcelas mais pobres da população. Tal fenômeno decorreria da necessidade de utilizar-se o direito penal como uma ferramenta de manutençâo das relaçóes de desigualdade presentes nas sociedades capitalistas. 
é sintoma do seletivismo penal que se instaurou no sistema carcerário nacional, onde se pune de forma mais contundente os crimes presentes em maior grau nas classes economicamente menos favorecidas, como é o caso dos delitos patrimoniais e daqueles relacionados ao tráfico de drogas.

A criminalização destes grupos vem acompanhada por um movimento de estigmatização, que acaba por considerá-los grupos propensos ao crime e que, por isso, são vistos como indivíduos irrecuperáveis. Assim, o cárcere torna-se o espaço destinado a sua neutralização, onde é aceitável que os presos sejam submetidos às maiores humilhaçóes e violações de direitos. Wacquant propóe, em tom crítico, que o encarceramento envolveria um tríplice estigma:

Atingidos por um tríplice estigma ao mesmo tempo moral (eles se baniram da cidadania ao violar a lei), de classe (eles são pobres em uma sociedade que venera a riqueza e concebe o sucesso social como resultado unicamente do esforço individual) e de casta (eles são majoritariamente negros, portanto oriundos de uma comunidade despida de "honra ética"), os detentos são o grupo pária entre os párias, uma categoria sacrificial que se pode vilipendiar e humilhar impunemente com imensos lucros simbólicos (2003, p. 97).

Deste modo, pode-se resumir que o panorama do atual modelo tradicional de gestáo carcerária oferece obstáculos ao processo de construção da identidade do encarcerado pautado no paradigma da autonomia. Em um ambiente majoritariamente superlotado, com péssimas condiçôes estruturais, onde há pouca oferta de trabalho e educação e onde se visualiza o cárcere como espaço destinado a segregação de determinados grupos sociais, existe mínima possibilidade de se realizar um trabalho comprometido com a reinserção social do apenado em condiçôes dignas.

\subsection{A consolidação e a perda do ideal humanizatório das penas}

Além das dificuldades estruturais também é possível elencar dificuldades de cunho conceitual que acabam por obstaculizar a realização de um trabalho dignificante com o encarcerado. Conforme será destacado, o atual modelo de gestáo carcerária não está pautado na busca pela reinserção social do apenado através do estímulo ao desenvolvimento de sua autonomia, haja vista que, historicamente, visualizou-se um processo de progressiva perda do caráter humanizado das penas.

A humanização das penas, cujo primado máximo foi a assunção da ressocializaçáo como uma de suas funções essenciais, passou - e ainda passa - por um gradual processo de implementação ao longo da história. Sua consolidação se confunde com as próprias transformaçôes ocorridas no âmbito do direito punitivo que, paulatinamente, tornou-se menos cruel e passou a calcar sua aplicação com base no respeito à dignidade humana.

Contudo, hodiernamente, atravessa-se um momento de crise dentro do sistema tradicional de execução penal, onde as recorrentes violaçôes aos direitos humanos dos encarcerados evidenciam o fracasso do projeto de ressocialização e lançam luz sobre a necessidade de serem pensados modelos alternativos. Para fundamentar a presente discussão será utilizado o referencial 
teórico desenvolvido pela criminologia crítica $^{3}$, cujas contribuiçóes auxiliarão na compreensão das vicissitudes ocorridas no sistema penal brasileiro.

Inicialmente, é preciso destacar que o período de transição do sistema feudal para o sistema capitalista foi marcado por uma reconstrução de diversos paradigmas existentes no campo penal. A ascensão do iluminismo, calcado em ideais humanistas, fundamentou a criação de um novo discurso no campo penal, onde "abandonou-se a vertente da vingança do soberano, fundada, abstrata e misticamente, em interesses divinos, e passou-se à punição dos homens como garantia concreta de manutenção do contrato social” (GUIMARÁES, 2007, p. 163).

A principal característica deste novo pensamento criminal se manifesta a partir do deslocamento do foco punitivo do corpo para a alma do apenado. As sançóes cruéis, cujos suplícios públicos eram sua principal manifestação, são substituídas pela pena de prisão, que assume o lugar de principal mecanismo punitivo. A ruptura com o regime absolutista e a assunção dos ideais de liberdade, igualdade e fraternidade, calcados na valorização humana, não mais admitiam a punição desmedida, marcada pela crueldade e pela tortura.

A virada promovida no pensamento criminal cria o caminho propício para a discussão da humanização das prisôes. Beccaria ${ }^{4}$ apresenta-se como um árduo defensor do processo de humanização do cárcere, principalmente ao criticar ferrenhamente o sistema punitivo absolutista, cuja manifestação cruel e desumana seria a demonstração da conservação de um pensamento barbáro e ultrapassado.

À medida que as penas forem mais brandas, quando as prisões já não forem a horrível mansão do desespero e da fome, quando a piedade e a humanidade penetrarem nas masmorras, quando enfim os executores impiedosos dos rigores da justiça abrirem os coraçôes à compaixão, as leis poderão contentar-se com indícios mais fracos para ordenar a prisão (BECCARIA, 2012, p. 40).

Adepto da teoria do contrato social desenvolvida por Thomas Hobbes, Beccaria (2012) destaca que a principal função da pena seria proteger o pacto social, evitando que os homens incorressem em açóes que remontassem ao estado de natureza, onde a desordem e a insegurança

3 Baratta (2011, p. 148) e Guimarães (2007, p. 66) destacam que a criminologia tradicional exercia uma função meramente instrumental em relação à dogmática penal, haja vista que todo conhecimento produzido se destinava a construção conceitual e a sistematização do direito penal oficial. Em suma, a criminologia exercia um papel auxiliar, fundamentando empiricamente a aplicação do direito repressivo. As teorias críticas surgem justamente com o objetivo de confrontar o discurso oficial estabelecido, discutindo o fenômeno delitivo a partir de enfoques diferenciados. O objetivo principal destas novas correntes seria deslocar o objeto de estudo da figura do criminoso (perspectiva microssociológica) para os processos de criminalização (perspectiva macrossociológica). A criminologia crítica trabalha com duas etapas principais no estudo de seus objetos. A primeira delas consiste no deslocamento do estudo do autor para as condiçôes objetivas e estruturais que estão na origem dos desvios. A segunda seria o deslocamento do estudo das causas do comportamento criminoso para os processos de criminalização. Baratta (2011, p. 160) aduz que ao enfoque biopsicológico contrapóe-se o macrossociológico, historicizando a análise do desvio e relacionando-o com as estruturas sociais, relaçóes de produção e distribuição de riquezas.

4 Além de Beccaria, cuja obra tratou de estabelecer diversos princípios e garantias ainda hoje empregados na seara criminal, a filosofia humanista do liberalismo clássico é difundida através das ideias de diversos autores, podendo-se destacar Voltaire, Howard, Marat e Bentham. 
reinam. Sendo assim, o Estado seria o detentor do monopólio do poder punitivo, o qual deveria ser exercido com parcimônia e proporcionalidade ${ }^{5}$, haja vista que a punição deveria ser aquela necessária para preservar o vínculo social, causando o menor dano possível ao criminoso.

Para que o castigo produza o efeito que dele se deve esperar, basta que o mal que causa ultrapasse o bem que o culpado retirou do crime. Devem contar-se ainda como parte do castigo os terrores que precedem a execução e a perda das vantagens que o crime devia produzir. Toda severidade que ultrapasse os limites se torna supérflua e, por conseguinte, tirânica (BECCARIA, 2012, p. 87).

A assunção deste novo ideário penal auxiliou marcantemente na consolidação do capitalismo liberal clássico ${ }^{6}$, cuja marca característica seria uma política de mínima intervenção estatal, pautada no respeito às liberdades civis e políticas. Todavia, perceba-se que, neste momento histórico, ainda não se visualizava uma preocupação com a reinserção social do encarcerado, pois a proteção social é colocada em foco principal. Este direcionamento só viria a surgir com a emergência do Estado Social, cuja principal faceta seria apresentada no período posterior a ocorrência das duas grandes guerras mundiais.

Os efeitos nefastos gerados pela autodestruição humana no período entre guerras destaca-se a ocorrência de verdadeiros genocídios, pautados, sobretudo, na ideia de superioridade racial, levando ao extermínio de minorias étnicas, como judeus e ciganos - fizeram emergir a necessidade de que fossem efetivados consensos internacionais capazes de amenizar o intenso processo de descarte da vida humana ocorrido neste interregno histórico ${ }^{7}$.

Neste contexto surgem os Sistemas Internacionais de Proteção aos Direitos Humanos, cuja preocupação central seria justamente humanizar os ordenamentos jurídicos nacionais através da consolidação de um grupo de direitos universais, garantidos independentemente de particularidades raciais, culturais, religiosas, dentre outras.

A este contexto de crise humanitária soma-se um crescente movimento de insurgência social contra as diretrizes do capitalismo liberal que, ao empregar uma política de mínima intervenção estatal, acabou por gerar um estado de profunda opressão e desigualdade social. Além disto, Guimarães (2007, p. 187-189) destaca que a difusão do pensamento marxista e a organização do movimento operário acabaram por gerar um acirramento social capaz de trazer insegurança e instabilidade às bases do sistema capitalista.

5 Beccaria se apresenta como um profundo defensor da corrente utilitarista, cujos ideais demandam que as açôes estatais sejam pautadas em um cálculo utilitário devendo estar comprometidas com a promoçấo da maior felicidade possível para o maior número de pessoas. Sendo assim, a funçâoo primordial da pena não seria promover o sofrimento e a vingança, mas, sobretudo, garantir a preservação da coesão social.

6 Guimarães (2007), baseado nos ensinamentos da criminologia crítica, pontua que a humanização das penas visualizada no capitalismo liberal clássico estaria atrelada à imposição da nova lógica de trabalho, pautada na produção em larga escala. O capitalismo necessitava de grandes contingentes obreiros para sua consolidação, sendo assim, o criminoso náo poderia ser descartado, mas deveria ser adaptado para inserção no mercado de trabalho, tornando-se economicamente funcional.

7 Para melhor compreensão deste período de transição histórica e de formaçấo dos Sistemas Internacionais de Proteçẫo aos Direitos Humanos verificar Comparato (2013) e Piovesan (2007). 
O arrefecimento dos ânimos demandava a transformaçáo do modelo liberal-capitalista. A saída encontrada foi a incorporação de um discurso mais humanizado, sendo o Estado chamado a intervir nas relaçóes sociais, reassumindo funçóes que haviam sido perdidas em virtude da incorporaçáo do laissez faire ${ }^{8}$ liberal. Neste contexto, surge a figura do Estado intervencionista, responsável pela efetivação dos direitos econômicos, sociais e culturais, capaz de perpassar a ideia de comprometimento do sistema capitalista com as demandas das classes menos abastadas.

Este momento histórico inaugura o surgimento da uma nova faceta do capitalismo, marcada pelo fortalecimento do Estado Social. Conforme Guimarães (2007, p. 193), tal transição também exige uma diferente feição do direito penal, preocupada com a conformação social pacífica, onde não mais se aceita que sua aplicação vise unicamente neutralizar ou intimidar os inimigos da sociedade, mas exige-se que tenha um comprometimento efetivo com a recuperação do ser humano, enfocando-se o caráter ressocializador da pena privativa de liberdade.

Contudo, como o objetivo principal do Estado Social não era promover uma maior justiça social, mas sim aplacar os movimentos de insurgência civil, não demorou para que suas bases se enfraquecessem. $\mathrm{O}$ recuo dos movimentos revolucionários, somado à dificuldade do Estado de se desincumbir das complexas tarefas prestacionais ${ }^{9}$, ocasionaram um gradual processo de enfraquecimento do Estado Social, criando as condiçôes propícias para uma nova forma de organização do sistema capitalista - surgida a partir de 1980 - denominada de neoliberalismo.

A nova política neoliberal possui como carro chefe o retorno ao modelo de intervenção mínima do Estado, só que agora associado ao novo mundo globalizado. Este novo paradigma demanda a eliminação de todo tipo de obstáculo ou protecionismo comercial, sendo destinado a garantir uma ampla abertura dos mercados capaz de propiciar uma concorrência ilimitada de âmbito internacional. A privatização, efetivada a partir do repasse de atividades estatais à iniciativa privada, retira do Estado a possibilidade de gerenciamento de setores estratégicos, diminuindo sua possibilidade de interferência em decisóes fundamentais para sociedade.

McChesney (2002) aduz que o neoliberalismo é o grande paradigma econômico e político dos novos tempos e seu principal objetivo consiste em estabelecer um conjunto de procedimentos destinados a garantir a maximização dos benefícios individuais de um pequeno grupo em detrimento dos interesses de grande parcela da população.

Guimarães (2007, p. 239) sustenta que o Estado neoliberal é a antítese do Estado Social, haja vista que toda sua formação tem como objetivo principal a blindagem e a satisfação dos interesses das classes dominantes. Uma de suas marcas consiste na progressiva redução dos investimentos em programas sociais que beneficiariam a maioria da população. Este cenário

8 A expressão é aqui empregada no sentido da autogestão dos mercados, através da mínima interferência estatal no campo econômico.

9 Conforme Maus (2000) e Barroso (2015), a destinação de uma série de prestaçóes positivas ao Estado gerou implicaçóes na formaçáo do direito constitucional de diversos países, sendo possível observar a proliferação de Constituiçôes programáticas, caracterizadas pela definição de pretensiosas metas na área social. A incapacidade estatal de cumprir as promessas constitucionais contribuiu significativamente para derrocada do Estado Social. 
afunda a parcela mais pobre da sociedade em um cenário de total invisibilidade perante as políticas estatais, onde sua humanidade é vilipendiada e sua cidadania apenas é encontrada ao se sentarem no banco dos réus.

As transiçôes geradas pela sociedade neoliberal também se fazem sentir de forma intensa no campo penal. A humanização ocorrida após o período de guerras é substituída por um discurso de maximização do direito penal onde é propagada a ideia de que todos os problemas sociais podem ser resolvidos através da expansão e do endurecimento das políticas criminais. Neste novo cenário, a violência estrutural, causa maior da criminalidade, é escamoteada. O crime é tratado como uma questão meramente individual, inserido dentro de uma lógica maniqueísta, como se a sociedade fosse composta por uma antítese entre "cidadãos de bem", que precisam ser valorizados e protegidos, e "inimigos", que precisam ser combatidos, neutralizados e, a depender do caso, eliminados.

Zaffaroni (2007, p. 59-69) sustenta que o principal exemplo mundial de transição do Estado Social para o Estado Penal ocorreu nos Estados Unidos, no período posterior a guerra fria. Os ideais neoliberais influenciaram fortemente na formação da nova política criminal norte-americana que, segundo o referido autor, possui como marca fundamental um discurso fortemente autoritário e bastante apelativo do ponto de vista emocional, destinado a aplacar a ânsia punitiva de uma sociedade revoltada com a incessante criminalidade.

A derrocada do inimigo soviético, anteriormente capaz de legitimar a aplicação de um direito penal mais repressivo, faz surgir a necessidade de construção de novas figuras infaustas. Neste ponto, a política de "guerra às drogas" assume um papel vital para a construção do novo Estado Penal norte-americano em que, sob a justificativa de combate ao crime, legitima-se a ampliação do aparato repressivo.

Wacquant (2003, p. 27) demonstra que, em meados do século XX, os Estados Unidos realizam uma guinada em sua política de investimentos, com o constante redirecionamento de recursos da área social ${ }^{10}$ para o campo da repressão criminal. Decaem os investimentos em políticas assistenciais e passa-se a centrar forças na construção de presídios e no fortalecimento das agências de repressão e controle da criminalidade ${ }^{11}$. Neste período ocorre a expansão da população carcerária, ampliando-se problemas estruturais como a seletividade penal, uma vez que a maioria dos detentos eram negros ou latinos. Conclui o autor que a principal característica da nova política criminal norte-americana seria empreender um processo de criminalização das camadas mais pobres da sociedade.

10 O autor denomina o antigo Estado Social norte-americano como "estado caritativo".

11 Zaffaroni (2007) e Wacquant (2003) destacam que a política de guerra às drogas norte-americana surge em um período em que os índices de criminalidade locais se mostravam estáveis e, em alguns casos, até mesmo decrescentes. Sendo assim, a nova política criminal dos Estados Unidos não se pautava numa urgente demanda de combate à criminalidade, mas sim decorria da assimilação dos novos valores neoliberais capitalistas que exigiam uma nova gestão do sistema penal. 
Todo este movimento ampara-se em uma narrativa sob a qual o direito penal seria capaz de solucionar o problema do exponencial crescimento da delinquência, sendo apresentado como a soluçáo para todos os problemas sociais. Este discurso se propaga e passa a ser amplamente utilizado pela classe política com fins eleitoreiros. Em uma sociedade revoltada com a criminalidade cotidiana os discursos que pregam maior repressão são facilmente aceitos pela grande massa que acredita que a criminalidade possui sua origem no benigno tratamento dispensado pelo Estado em relação aos agentes delituosos.

Zaffaroni (2007, p. 69) aduz que o novo discurso penal assumido nos Estados Unidos, posteriormente importado para a América Latina, é vendido como uma verdadeira propaganda publicitária. Não há uma preocupação com a (in)efetividade daquilo que está sendo propagado, mas apenas que seja aceito pelo grande público, gerando um transitório momento de satisfação ${ }^{12}$.

$\mathrm{O}$ aparato repressivo passa a assumir uma feição eminentemente simbólica, sendo sua função precípua a de apaziguar os ânimos de uma sociedade insatisfeita. Para o cumprimento desta finalidade é necessário que o sistema penal aja de forma rápida e dura, ainda que isto implique em verdadeiro vilipêndio aos direitos fundamentais dos investigados.

Soma-se a este processo um movimento de despersonalização e desvalorização da individualidade, onde todos os encarcerados são tratados como se fossem iguais, ou seja, como uma massa indistinta de sujeitos. Exemplo maior deste fenômeno consiste no fato de que o apenado passa a usar "roupas uniformizadas, assim como os cortes de cabelo e medidas de tratamento padronizadas, sendo reflexos da perda da individualidade" (BARRETO, 2006, p. 589).

Goffman (1987) destaca que este tipo de abordagem acaba por perpetrar um processo de "mortificação do eu", cuja característica principal seria a ruptura com todos os vínculos sociais em prol da entrada no ambiente institucional. Sua profissão, suas habilidades e os seus hábitos não encontram mais espaço no mundo da instituição (MACEDO, 2004, p. 4).

Todo este movimento histórico denota que a humanização das penas - conquista histórica obtida à custa do sacrifício de inúmeras vidas - tem sido paulatinamente esquecida, tudo isto em prol do expansionismo punitivo que torna o cárcere um mero depósito de seres humanos, havendo um estímulo a sua obediência, sua passividade e seu fechamento existencial. Todavia, o atual modelo social exige um indivíduo ativo, reconstrutor de sua própria identidade, sendo capaz de assumir novos papéis sociais. Neste aspecto, apresentar-se-á no tópico seguinte o modelo de execuçáo penal desenvolvido pela APAC, cujo princípio basilar da valorização humana, permite uma maior aproximação com a retomada do processo de humanização do cárcere.

12 Zaffaroni (2007, p. 69) denomina este movimento como "autoritarismo cool”, pois não é assumido como uma convicção profunda, mas apenas enuncia aquilo que está na moda, aquilo ao qual é preciso aderir para não ser estigmatizado como antiquado, para que não se perca espaço publicitário. 


\section{0 método APAC: avanços e desafios}

O método APAC se originou na cidade de São José dos Campos - São Paulo, através do esforço de um grupo de quinze cristáos integrantes da pastoral carcerária local, liderados pelo advogado e idealizador do método Mario Ottoboni. Os esforços pela criação do método surgiram a partir de uma inquietação com os altos índices de reincidência existentes no ambiente carcerário. Inquietação esta que acabou por instigar a busca por novas alternativas para a execução penal, que melhor atendessem ao primado essencial da ressocialização.

A primeira experiência de aplicação da metodologia ocorreu na penitenciária de Humaitá, localizada na própria cidade de São José dos Campos. Neste momento o grupo atuava sob a denominação "Amando o Próximo, Amarás a Cristo". Em face dos êxitos alcançados verificouse a possibilidade de estender o método para outros locais o que culminou com a criação da APAC, no ano de 1974, sendo uma entidade civil de direito privado, sem finalidade lucrativa e com personalidade jurídica própria, que exerce suas atividades a partir de convênios com a Administração Pública (FALCÃO, 2013).

O sucesso da metodologia espalhou-se pelo país, sendo que, segundo a Fraternidade Brasileira de Assistência aos Condenados (2019), existem, atualmente, 51 APACs em funcionamento e outras 77 em processo de implementação, onde se encontram cumprindo pena 3.612 pessoas. Além disso, a média de reincidência dos indivíduos submetidos ao método APAC seria de, aproximadamente, 15\%. Também é válido ressaltar que os êxitos da metodologia fizeram com que esta fosse exportada, sendo que, atualmente, mais de 30 países já incorporaram o método APAC.

Como atua a partir de convênios com a Administração Pública a APAC submete-se às diretrizes da Constituição Federal, do Código Penal e da Lei de Execuçôes Penais, sendo que os juízes e o Tribunal de Justiça participam da execução e do monitoramento de suas atividades.

Os principais pilares do método APAC são a valorizaçáo humana, o respeito a individualidade do encarcerado, a reinserção através da preservação dos vínculos sociais e comunitários e a reflexão moral. Ottoboni (2006, p. 29) dispóe que "trata-se de um método de valorização humana, voltado para oferecer ao condenado condiçóes de recuperar-se, logrando, dessa forma, o propósito de proteger a sociedade e promover a justiça”.

Segundo a Cartilha APAC, elaborada pelo Projeto Novos Rumos, o método possui doze elementos fundamentais, que orientam as diretrizes de atuação de todas as unidades, sendo eles: a participação da comunidade, o trabalho, a religião, a assistência jurídica, a assistência à saúde, valorização humana, a família, o voluntariado, o lema "recuperando ajudando recuperando", o Centro de Reintegração Social, o mérito e a Jornada de Libertação com Cristo (MINAS GERAIS, 2009). Neste trabalho, tratar-se-á, primordialmente, de algumas destas diretrizes, dada sua pertinência ao tema em estudo. Desse modo, analisar-se-á a participaçáo da comunidade, o trabalho, a religião e a valorização humana. 


\subsection{Valorização Humana}

Trata-se do pilar base da metodologia, sendo que todos os demais pressupostos devem ser interpretados a partir desta diretriz central. Toda a dinâmica proposta pela APAC baseia-se na existência de uma visão positiva acerca do encarcerado, pois ao invés de ser tratado como um sujeito potencialmente perigoso, acredita-se plenamente em sua recuperação. Por isto, ao apenado é dado o papel de protagonismo na execução penal, participando ativamente da gestão da instituição. Exemplo maior reside no fato de que os próprios presos realizam a segurança do ambiente prisional, sendo responsáveis pelo cumprimento da rotina carcerária.

Um dos pontos onde se manifesta a valorização consiste na pessoalidade do tratamento dado ao encarcerado. Ottoboni (2014, p. 87) destaca que pequenas medidas como chamá-lo pelo nome, interessar-se pela sua vida, visitar sua família, permitir que se sente à mesa para fazer as refeiçôes diárias, são medidas que colocam em primeiro lugar o ser humano, não resumindo o indivíduo ao fato delitivo cometido.

Diferentemente do modelo tradicional, onde o encarcerado é envolvido num processo de assujeitamento, no método APAC a sua história de vida é valorizada, seus laços sociais anteriores são mantidos e reestruturados. Neste processo, o recuperando é visto como sujeito cheio de potencialidades, afastando-se o estigma negativo que paira sobre a sua figura.

Todavia, o método APAC alia este sistema de valorização com uma diretriz essencialmente pautada na disciplina. A obediência a um cronograma de atividades pré-elaborado e o rigor são elementos essenciais dentro da metodologia. Lima e Pasti (2016), em estudo realizado sobre algumas unidades da APAC, destacam que o rigor é um pilar essencial do método, sendo que o controle é realizado até mesmo nos momentos mais banais do cotidiano.

A rigidez da rotina, contudo, ficou clara em ambas as unidades, principalmente em relação aos horários, determinados para todas as atividades do dia, até mesmo para fumar, o que, conforme os próprios presos e presas ouvidos narram, causa uma certa dificuldade na adaptação dos internos, sendo que há inclusive um 'período de adaptação', de três meses, no qual os recém chegados a APAC podem, caso não desejem se submeter à disciplina e às regras, ou entendam que não se adaptaram ao método, solicitar ao juiz da Execuçáo Penal, seu retorno ao 'sistema comum' (LIMA; PASTI, 2016, p. 92).

Falcão (2013, p. 53) traduz o mesmo pensamento, aduzindo que o "apenado é protagonista de sua recuperação, tornando-se corresponsável por ela, estabelecendo-se uma disciplina rígida aos presos, em que prima-se pelo respeito, pela ordem e pelo trabalho".

Neste ponto, percebe-se uma aproximação da APAC com o modelo tradicional de execução penal, principalmente em virtude da utilização do poder disciplinar. Deste modo, pode-se destacar uma aparente contradição, pois o método desenvolve uma série de atividades que buscam realçar a autonomia dos apenados (estímulo ao trabalho, educação, convivência familiar, protagonismo na gestão carcerária, etc.), todavia, a organização da rotina dos indivíduos 
é feita a partir de diretrizes do poder disciplinar que pleiteia o objetivo oposto, que consiste em docilizar os indivíduos, minando sua autonomia e tornando-os sujeitos passivos.

\subsection{Participação da comunidade}

O envolvimento da comunidade no processo de execução penal é uma das diretrizes da metodologia APAC, sendo considerado ponto essencial no processo de reconstruçáo dos laços sociais do apenado. Afinal, a comunidade é o local onde o indivíduo desenvolverá sua vida póscárcere, sendo uma das principais instâncias interessadas pelos benefícios trazidos por uma plena ressocialização do encarcerado.

Com isto, parte-se do pressuposto que a execução penal não é tarefa unicamente cabível ao Estado, como ocorre no modelo tradicional, mas que deve envolver também a participação da sociedade civil. A própria Lei de Execuçôes Penais, em seu artigo $4^{\circ}$, traça essa diretriz ao dispor que o "Estado deverá recorrer à cooperação da comunidade nas atividades de execução da pena e da medida de segurança” (BRASIL, 1984). Exemplo maior deste modelo reside no primado da voluntariedade, sendo que os funcionários da APAC são membros da comunidade que se dispóem de forma graciosa a realizar o trabalho ${ }^{13}$.

Ottoboni (2014) dispóe que o êxito do sistema prisional perpassa a descentralização dos presídios, com cada comunidade assumindo sua população prisional, através de um modelo de cogestão penitenciária entre o Estado, entidades organizadas juridicamente e a sociedade civil. Sem uma medida desta natureza nenhum resultado será alcançado, por mais primorosa que seja a legislação vigente.

Para a concretização deste direcionamento é essencial que seja respeitado o princípio da municipalização da pena, garantindo que o cumprimento das penas privativas de liberdade seja realizado o mais próximo possível dos locais onde os indivíduos residam ou tenham família para que, assim, possuam um sentimento de pertencimento em relação àquele espaço social (FALCÃO, 2013).

Dito isto, o modelo APAC parece diferir significativamente do modelo tradicional, pois parte-se do pressuposto que o processo de reconstrução da identidade do encarcerado deve ser realizado através da manutenção e da reestruturação dos vínculos entre o indivíduo e o seu núcleo social. Deste modo, os vínculos anteriores do apenado são valorizados e encarados como parte essencial do processo de ressocialização. Não se mortifica o sujeito preexistente, mas reestruturase sua rede de relaçóes.

\subsection{O trabalho}

13 Em que pese a preferência pelo voluntariado, diversas unidades da APAC contam com funcionários contratados em sua estrutura. Isto ocorre, em geral, pela ausência de voluntários suficientes ou pela impossibilidade de dedicação integral ao trabalho com os apenados. Contudo, mesmo nestas situaçóes, a participação da comunidade continua sendo ponto primordial da metodologia, uma vez que as atividades organizadas (oficinas, torneios esportivos, etc.) primarão pela interação da sociedade com as pessoas encarceradas. 
O trabalho faz parte do contexto e da metodologia APAC, todavia não é o único elemento fundamental, pois ele sozinho não é capaz de promover a recuperação do sujeito. O modo de realização do trabalho varia de acordo com o regime ao qual o indivíduo está submetido, cada etapa é marcada por uma inserção gradual do apenado ao mundo de trabalho, de modo que não seja inserido imediatamente em um ambiente desestimulante e maçante.

No regime fechado privilegia-se a prática da laborterapia, através de atividades como o artesanato. $\mathrm{O}$ trabalho é realizado dentro do ambiente prisional e os produtos são comercializados, sendo que o apenado recebe um retorno financeiro. Já no regime semiaberto há um maior foco na definição de uma profissão, admitindo-se saídas para estudos, participação em cursos técnicos e até mesmo a realização de trabalhos externos.

No que diz respeito ao regime aberto busca-se reproduzir uma situação de total reintegração social do apenado, passando a desempenhar a profissão escolhida de forma integralmente externa, integrando-se à comunidade, sendo o último passo antes do retorno ao convívio social.

\subsection{A religião}

Trata-se, sem dúvidas, da diretriz mais polêmica presente no método APAC. Os maiores questionamentos residem na compatibilidade entre a metodologia e a laicidade própria do Estado. Alguns dos estudiosos da metodologia aduzem que os encarcerados devem, obrigatoriamente, possuir uma religião, não havendo, contudo, a imposição de nenhum credo. Neste sentido, Falcão (2013, p. 55) sustenta que "a transformação moral do condenado dar-se-á por meio da religião onde, sem que haja, em teoria, a imposição de credos, o preso tem que, imperiosamente, possuir uma religião". Ottoboni também partilha similar entendimento:

A religião é fator primordial, a experiência de Deus de amar e ser amado, é de uma importância incomensurável, desde que pautada pela ética e dentro de um conjunto de propostas em que a reciclagem dos próprios valores leve o recuperando a concluir que Deus é o grande companheiro (2001, p. 78).

Deste modo surgem questionamentos sobre a possibilidade de serem realizadas parcerias entre a Administração Pública e a APAC, pois, tendo em vista que o Estado Brasileiro é laico, seria inviável a destinação de recursos públicos para uma entidade que partilha preceitos religiosos específicos. Seria um modo de, indiretamente, financiar uma determinada religiáo ${ }^{14}$.

Todavia, outros autores, como Andrade (2015), entendem que o objetivo da APAC náo seria obrigar o preso a se filiar a uma religião específica, mas sim proporcionar sua reflexão moral, através de atividades e momentos específicos voltados para ressignificação dos valores. Deste modo, o indivíduo náo precisaria optar por uma doutrina religiosa, mas sim engajar-se com os processos reflexivos.

14 Neste sentido consultar Soares (2011) e Silva (2011). 
Alguns estudos, como os realizados por Silva Júnior (2014) e Vargas (2011), concluíram que o modo como são organizadas as APACs, apesar de atuarem sob o paradigma do respeito à liberdade religiosa, acaba por influenciar os apenados a optarem por uma determinada crença. Destacam que este fenômeno se manifesta através do oferecimento de apenas alguns cultos religiosos (principalmente, católicos ou evangélicos) e também na própria arquitetura do ambiente institucional, com a presença de quadros, imagens, frases e símbolos de uma religião específica.

Vargas (2011, p. 171) dispóe que, quando organizadas da forma acima descrita, as APACs acabam por valorizar um protótipo de sujeito ideal, impondo um modelo de identidade ao apenado. Neste sentido, a execução penal não seria essencialmente distinta daquela efetuada pelo modelo tradicional, pois sufocaria a autonomia dos indivíduos.

Mais do que um processo de desestigmatização negativa, parece-me que nas APACs se leva a cabo, o que poderíamos chamar de processo de reestigmatização, considerado positivo, que propóe outros tipos de relaçóes, de etiquetas e de identidades e que opera como um eficiente dispositivo de poder que estabelece, náo somente no discurso, mas também na prática, um tipo particular de sujeito: o modelo ideal de sujeito apaqueano.

Todavia, os estudos acima destacados tratam de unidades específicas da APAC, não sendo viável a generalização dos seus resultados. Sendo assim, não se pode definir que exista um modo uniforme de aplicação das diretrizes religiosas. Contudo, é possível dizer que, naquelas unidades onde há um predomínio maior de uma ou algumas doutrinas religiosas há uma maior tendência que os encarcerados sejam submetidos a um processo coercitivo de aceitação de determinadas crenças. Este movimento dificultaria a existência de um processo de identitário dos encarcerados baseado na valorização de sua autonomia, se assemelhando às diretrizes do modelo disciplinar. Todavia, se a APAC for um ambiente aberto para todas as religióes, com liberdade participativa, este será um aspecto reforçador da autonomia do sujeito, uma vez que poderá dispor livremente sobre a necessidade de participar de um culto religioso.

\section{Consideraçóes finais}

De acordo com o exposto, percebe-se que o modelo tradicional de gestão carcerária não apresenta um contexto propício para a ressignificação do processo identitário do encarcerado. As insuficiências estruturais, somadas à perda do caráter humanizado das penas, cuja ressocialização constitui o objetivo máximo, acabam por formar um indivíduo incapaz de adaptar-se às exigências do mundo moderno e globalizado, o qual demanda do sujeito a assunção de papéis de protagonismo, através da apropriação de um modelo autônomo de identidade.

Os altos índices nacionais de encarceramento não são capazes de trazer à sociedade o sentimento de tranquilidade, justamente porque prende-se muito, mas não se visualizam grandes discussóes ou preocupaçóes acerca do momento posterior à entrada no cárcere. 
Todo este panorama traz à tona a necessidade de se refletir acerca de modelos alternativos de execução penal. Neste contexto, a metodologia desenvolvida pela Associação de Assistência e Proteção aos Condenados (APAC) surge como uma esperança, se apresentando como um método pautado na valorização humana, tendo como pilares o respeito à individualidade e à autonomia do condenado. Além disto, pleiteia que o cumprimento da pena náo deve implicar uma total segregação do encarcerado com o seu meio social. Pelo contrário, é necessário que a comunidade participe ativamente deste processo, haja vista que é ela quem receberá este indivíduo posteriormente.

Todas estas características contribuem para que o processo de construção da identidade do encarcerado seja pensado através do paradigma da autonomia, valorizando a assunção de papéis de protagonismo social por parte do encarcerado.

É válido ressaltar que a metodologia APAC ainda apresenta pontos controversos, capazes de conduzir ao fechamento existencial dos apenados, veja-se que a obediência e o rigor - medidas coercitivas por excelência - no cumprimento das tarefas são pilares fundamentais do método. Além disto, a questão da religiáo precisa ser delicadamente trabalhada dentro deste modelo de execuçáo penal para que se preserve o respeito à laicidade estatal. Contudo, apesar destes desafios, é possível visualizar que tal metodologia se apresenta muito mais condizente com às diretrizes dos grandes tratados internacionais de Direitos Humanos, da Constituição Federal e da Lei de Execuçóes Penais.

O que não se pode admitir é que as prisóes continuem sendo grandes depósitos de seres humanos e que as pessoas ali alocadas sejam vistas como sujeitos irrecuperáveis, verdadeiros inimigos da sociedade. É essencial que os modelos de execução penal identifiquem o crime como um fenômeno social e, a partir disto, tentem trabalhar, na medida do possível, suas causas e, para isto, é necessário que se valorize a humanidade de cada sujeito.

\section{Referências}

ANDRADE, Durval Ângelo. APAC: a face humana da prisão. 3. ed. Belo Horizonte: Expressa, 2015.

BARATTA, Alessandro. Criminologia Crítica e Crítica ao Direito Penal: introdução à sociologia do Direito Penal. 6. ed. Rio de Janeiro: Revan, 2011.

BARRETO, Mariana Leonesy da Silveira. Depois das grades: um reflexo da cultura prisional em indivíduos libertos. Psicologia, Ciência e Profissão, Brasília - DF, v. 26, n. 4, p. 582-593, 2006.

BARROSO, Luís Roberto. Curso de Direito Constitucional Contemporâneo: Os conceitos fundamentais e a Construção do Novo Modelo. São Paulo: Saraiva, 2015. 
BAUMAN, Zygmunt. O mal-estar da pós-modernidade. Rio de Janeiro: Jorge Zahar Editores, 1998.

BECCARIA, Cesare. Dos delitos e das penas. Tradução: Neury Carvalho Lima. São Paulo: Hunter Books Editora, 2012.

BENELLI, Silvio José. Goffman e as instituições totais em análise. In: BENELLI, Silvio José. A lógica da internaçáo: instituiçóes totais e disciplinares (des)educativas. São Paulo: Editora Unesp, 2014. p. 23-62.

BRASIL. Lei n ${ }^{\circ}$ 7.210, de 11 de julho de 1984. Institui a Lei de Execução Penal. Diário Oficial da União, Brasília, DF. 13 jul. 1984. Disponível em: <http://www.planalto.gov.br/ ccivil_03/leis/17210.htm>. Acesso em: 20.jun.2019.

BRASIL. Ministério da Justiça. Departamento Penitenciário Nacional. Levantamento de informaçóes penitenciárias - junho de 2016. Brasília - DF, 2016.

BRASIL. Ministério da Justiça. Departamento Penitenciário Nacional. Levantamento de informaçóes penitenciárias - junho a dezembro de 2019. Brasília - DF, 2019.

CAMARGO, Amilton Carlos; FERREIRA, Ricardo Franklin. Preconceito, exclusão e identidade do afrodescendente. In: CARVALHO, Isalena Santos; FERREIRA, Ricardo Franklin (orgs.). Processos de exclusáo na sociedade contemporânea. São Luís: Edufma, 2013.

CIAMPA, Antonio da Costa. Identidade. In: LANE, Silva T. Mauer; CODO, Wanderleu. (Orgs.). Psicologia Social: o homem em movimento. São Paulo: Brasiliense, 1984.

COMPARATO, Fábio Konder. A afirmaçáo histórica dos direitos humanos. 8. ed. São Paulo: Saraiva, 2013.

FALCÃO, Ana Luíse Silva. O sistema prisional e a associaçáo de proteçáo e assistência aos condenados - APAC: uma análise sob a perspectiva da lei de execuções penais - LEP. Fundação João Pinheiro: Belo Horizonte, 2013.

FERNANDES, Bernardo Gonçalves. Curso de direito constitucional. 5. ed. Juspodivm: Sáo Paulo, 2013.

FRATERNIDADE BRASILEIRA DE ASSISTÊNCIA AOS CONDENADOS. Relatório sobre as APACs. 2019. Disponível em: <http://www.fbac.org.br/infoapac/relatoriogeral.php>. Acesso em: 22.jun.2019.

GOFFMAN, Erving. Manicômios, prisóes e conventos. 2. ed. São Paulo: Perspectiva, 1987.

GUERRA, Sidney. Direitos Humanos. São Paulo: Saraiva, 2003.

GUIMARÃES, Cláudio Alberto Gabriel. Funçóes da pena privativa de liberdade no sistema penal capitalista. 2. ed. Rio de Janeiro: Revan, 2007. 
JAKOBS, G.; MELIÁ, Manuel Cancio. Direito Penal do Inimigo: noções e críticas. 6 ed. Porto Alegre: Livraria do Advogado, 2018.

LIMA, Lana Lage da Gama; PASTI, Nayara Moreira Lisardo. Representaçóes de gênero na aplicação do método APAC em Itaúna - MG. 2016. Disponível em: <http://www. periodicos.ufes.br/dimensoes/article/view/13846/9801>. Aceso em: 15.jun.2019.

MACEDO, Paulo. A pena de prisão no Brasil: uma análise à luz da sociologia do direito de Erving Goffman. Revista da Esmese, Aracajú, n. 7, p. 257-267, 2004.

MCCHESNEY, Robert. Introdução ao livro O lucro ou as pessoas: neoliberalismo e ordem global. In: CHOMSKY, Noam. O lucro ou as pessoas: neoliberalismo e ordem global. Rio de Janeiro: Bertrand Brasil, 2002.

MINAS GERAIS. Tribunal de Justiça. Projeto Novos Rumos. Todo homem é maior que seu erro. Belo Horizonte, 2009.

OTTOBONI, Mário. Ninguém é irrecuperável: APAC - a revolução do sistema penitenciário. 2. ed. São Paulo: Cidade Nova, 2001.

OTTOBONI, Mário. Somos todos recuperandos. Belo Horizonte: AVSI Brasil, 2014.

OTTOBONI, Mário. Vamos matar o criminoso? 3. ed. São Paulo: Paulinas, 2006.

PIOVESAN, Flávia. Direitos humanos e justiça internacional: um estudo comparativo dos sistemas regionais europeu, interamericano e africano. São Paulo: Saraiva, 2007.

SARLET, Ingo Wolfgang. Dignidade da pessoa humana e direitos fundamentais na

Constituiçáo Federal de 1988. 9. ed. Porto Alegre: Livraria do Advogado Editora, 2011.

SILVA, Haroldo Caetano. Estado Penal e funçôes do cárcere na contemporaneidade: produção de subjetividade e criminalidade. In: Conselho Federal de Psicologia. Atuaçáo do psicólogo no sistema prisional. Brasília - DF, 2011. p. 33-43.

SILVA, Artenira da Silva; MATTOS, Delmo; CHAVES, Denisson Gonçalves. Deficiência na prisão frente a uma revisáo crítica criminológica. Revista Direito e Justiça: Reflexôes Sociojurídicas, Santo Ângelo, v. 18, n. 30, 2018.

SILVA JÚNIOR, Antônio Carlos da Rosa. Recuperação religiosa de presos: os (não) cristãos no método APAC de cumprimento de pena. Minas Gerais: UFJF, 2014.

SOARES, Evânia França. Uma reflexáo sobre as APACs. Revista do CAAP, Belo Horizonte, v. 17, n.2, p. 73-93, 2011.

VARGAS, Laura Jimena Ordoñez. É possível humanizar a vida atrás das grades? Uma etnografia do método de gestão carcerária APAC. Brasília - DF: UNB, 2011. 
WACQUANT, Loic. Punir os pobres: a nova gestão da miséria nos Estados Unidos. Rio de Janeiro: Revan, 2003.

ZAFFARONI, Eugenio Raul. O inimigo no direito penal. Trad. Sérgio Lamarão. Rio de Janeiro: Revan, 2007. 